\title{
Targeted delivery of biodegradable nanoparticles with ultrasound-targeted microbubble destruction-mediated hVEGF-siRNA transfection in human PC-3 cells in vitro
}

\author{
YUN-HUA LI $^{1 *}$, QIU-SHENG SHI ${ }^{1 *}$, JING DU $^{1}$, LI-FANG JIN ${ }^{1}$, LIAN-FANG DU ${ }^{1}$, \\ PEI-FENG LIU ${ }^{2}$ and YOU-RONG DUAN ${ }^{2}$ \\ ${ }^{1}$ Department of Ultrasound, Shanghai First People's Hospital Affiliated to Shanghai Jiaotong \\ University School of Medicine, Shanghai 200080; ${ }^{2}$ Cancer Institute of Renji Hospital Affiliated \\ to Shanghai Jiaotong University School of Medicine, Shanghai 200032, P.R. China
}

Received August 14, 2012; Accepted October 15, 2012

DOI: $10.3892 / \mathrm{ijmm} .2012 .1175$

\begin{abstract}
A potentially viable approach for treating latestage prostate cancer is gene therapy. Successful gene therapy requires safe and efficient delivery systems. In this study, we report the efficient delivery of small interfering RNA (siRNA) via the use of biodegradable nanoparticles (NPs) made from monomethoxypoly(ethylene glycol)-poly(lactic-co-glycolic acid)-poly-1-lysine (mPEG-PLGA-PLL) triblock copolymers. On the basis of previous findings, cyclic Arg-Gly-Asp (cRGD) peptides were conjugated to NPs to recognize the target site, integrin $\alpha v \beta 3$, expressed in high levels in PC-3 prostate cancer cells. The suppression of angiogenesis by the downregulation of vascular endothelial growth factor (VEGF) expression has been widely used to inhibit the growth of malignant tumors. In our study, human VEGF (hVEGF)-siRNA was encapsulated in NPs to inhibit VEGF expression in PC-3 cells. Concurrently, sonoporation induced by ultrasound-targeted microbubble destruction (UTMD) was utilized for the delivery of siRNAloaded NPs. Our results showed low cytotoxicity and high gene transfection efficiency, demonstrating that the targeted delivery of biodegradable NPs with UTMD may be potentially applied as new vector system for gene delivery.
\end{abstract}

Correspondence to: Dr Lian-Fang Du, Department of Ultrasound, Shanghai First People's Hospital Affiliated to Shanghai Jiaotong University School of Medicine, 85 Wu Jin Road, Shanghai 200080, P.R. China

E-mail: du_lianfang@163.com

Dr You-Rong Duan, Cancer Institute of Renji Hospital Affiliated to Shanghai Jiaotong University School of Medicine, 2200 Xie Tu Road, Shanghai 200032, P.R. China

E-mail: yrduan@shsci.org

${ }^{*}$ Contributed equally

Key words: ultrasound-targeted microbubble destruction, cyclic arginine-glycine-aspartic acid peptides, nanoparticles, gene transfection, small interfering RNA, vascular endothelial growth factor, human PC-3 cells

\section{Introduction}

The vascular endothelial growth factor (VEGF) is considered a major factor mediating endothelial cell survival, migration, and proliferation during angiogenesis, and has been shown to be upregulated in various types of tumor cells and also plays a major role in prostate carcinoma development $(1,2)$. Therefore, the inhibition of VEGF expression has been considered as a potential approach for cancer therapy (3-5). RNA interference (RNAi), initiated by small interfering RNA (siRNA), induces the sequence-specific degradation of complementary mRNA and leads to the loss of target gene expression $(6,7)$. Human VEGF (hVEGF)-siRNA has been used to silence VEGF expression in PC-3 cells. However, inherent instability along with poor or non-specific cellular uptake has limited its usefulness.

The application of non-viral systems for gene delivery is being increasingly advocated due to low immunogenicity, unlimited payload capacity, absence of endogenous viral recombination, as wel as low production costs. Nanoparticles (NPs) that are non-toxic, biocompatible and biodegradable have been widely used as efficient carrier materials for gene delivery. In our previous study, mPEG-PLGA-PLL triblock copolymers were constructed for siRNA delivery (8). The NPs could successfully transfered siRNA into the tumor cells, and demonstrated higher gene inhibition efficiency than the control groups, while showing no cytotoxicity (8). On the basis of previous findings, this study focused on the surfacemodification of mPEG-PLGA-PLL triblock copolymers with cyclic arginine (Arg)-glycine (Gly)-aspartic acid (Asp) (cRGD) ligands to recognize the target site, integrin $\alpha v \beta 3$, expressed in high quantities in activated endothelial cells and certain tumor cells $(9,10)$, including PC-3 prostate cancer cells (11). The ligand binding of the cRGD peptide is expected to significantly enhance the ability of mPEG-PLGA-PLL-cRGD to bind to PC-3 cells and targeted NPs (TNPs) are expected to be a powerful vector for effective gene therapy against cancer. In our study, human-VEGF-siRNA was encapsulated in TNPs to inhibit VEGF expression in PC-3 cells. Non-targeted NPs (NNPs) were also encapsulated as the control. 
Ultrasound-targeted microbubble destruction (UTMD) has been proven to enhance gene transfer and may serve as a potential site-specific gene transfer modality. Sonoporation induced by UTMD leads to the transient and reversible increase in the permeability of cell membranes when exposed to ultrasound. In our previous as well as other studies, UTMD was utilized to facilitate the transfer of siRNA-loaded NPs across the cell membrane $(12,13)$. Although the process of sonoporation is not yet well understood and the bioeffects of sonoporation are similar to the side-effects (14-16), the transient and long-term viability of PC-3 cells did not decrease significantly under optimized experimental conditions. This study aimed to explore the efficient and safe delivery of siRNA for cancer therapy.

\section{Materials and methods}

Cell culture. Human prostate carcinoma cells (PC-3, Chinese Academy of Sciences) were maintained in RPMI-1640 medium containing $10 \% \mathrm{FBS}$, penicillin $(100 \mathrm{U} / \mathrm{ml})$ and streptomycin $(100 \mu \mathrm{g} / \mathrm{ml})$ at $37^{\circ} \mathrm{C}$ in a humidified incubator with $5 \% \mathrm{CO}_{2}$. Cell culture reagents were all purchased from Gibco (Grand Island, NY, USA). Cells were plated on a 12 -well plate at a density of $1.5 \times 10^{5}$ cells/well.

Ultrasound exposure protocol. A therapeutic US machine (Physiomed, Erlangen, Germany) was used and the area of the probe $(1 \mathrm{MHz})$ was $\sim 6.15 \mathrm{~cm}^{2}$. The groups were exposed to optimized ultrasound conditions (power, $1.2 \mathrm{~W} \mathrm{~cm}^{-2} ; 20 \%$ duty cycle; exposure time, $20 \mathrm{sec}$ ). The SonoVue powder (Bracco, Milan, Italy) was mixed with $5 \mathrm{ml}$ saline. After agitation for $30 \mathrm{sec}$, white galactoid microbubble suspension was prepared.

Preparation of mPEG-PLGA-PLL NPs loading siRNA. The preparation methods of $m$ PEG-PLGA-PLL siRNA-loaded NPs and their physicochemical characterization have been described in our previous study (8). The particle size of the siRNA-loaded NPs increased as the hVEGF-siRNA molecules were encapsulated in the inner water phase of mPEG-PLGAPLL NPs and cyclic Arg-Gly-Asp (cRGD) peptides were conjugated to the surface of the NPs. NPs loaded with siRNA but without cRGD were also constructed as the control. The NPs were termed TNPs and NNPs. The siRNA-loaded NPs were observed under an atomic force microscope (MultiMode 8; Veeco-Bruker, USA) and were shown to be spherical in shape. The mean diameter of the NPs was $\sim 112.0 \pm 4.0 \mathrm{~nm}$ (Fig. 1). All reagents for NPs were purchased from Shanghai Yuanju Biotechnology Co. (Shanghai, China).

SiRNA targeting human VEGF labeled with or without Cy3 and cRGD were purchased from RayBiotech, Inc., Guangzhou, China. Sequences were as follows: sense, 5'-GGAGUACCCUG AUGAGAUCdTdT-3' andantisense,5'-GAUCUCAUCAGGGUA CUCCdTdT-3'.

Experimental grouping. In this study, the cells were divided into the following 4 groups: i) the control group P, PC-3 cells with $60 \mu \mathrm{l}$ PBS; ii) the control group S, PC-3 cells with $60 \mu 1$ siRNA; iii) the control group N, PC-3 cells with $60 \mu 1$ NNPs loaded with siRNA; and iv) the test group T, PC-3 cells with $60 \mu 1$ TNPs loaded with siRNA. Each group was then devided into 3 subgroups: 1, no ultrasound (P1, S1, N1, T1); 2, ultra- sound alone (P2, S2, N2 and T2); and 3, ultrasound $+80 \mu 1$ SonoVue microbubbles (P3, S3, N3 and T3).

The mixture volume per well was added to $1 \mathrm{ml}$ with culture medium and the final concentration of siRNA was adjusted to $0.03 \mathrm{pmol} / \mu \mathrm{l}$ in the different groups. All experiments were carried out in triplicate.

Transfection. We compared the cellular uptake efficiencies of the different groups of cells as mentioned above. Cells were plated on a 12 -well plate at a density of $1.5 \times 10^{5}$ cells/well. After $48 \mathrm{~h}$ of incubation, the medium was replaced by fresh medium containing $10 \% \mathrm{FBS}$ and the desired siRNA formulations were added to the cells. siRNA labeled with fluorescent $\mathrm{Cy} 3$ dyes was used to examine the uptake of PC-3 cells. After $48 \mathrm{~h}$ of incubation, a fluorescent microscope was used for observation and the quantitative cellular uptake of Cy3-siRNA was estimated using a FACSCalibur flow cytometer. NNPs (without cRGD) loaded with siRNA were observed in the perinuclear cytoplasmic region in our previous studies. The intracellular localization of TNPs but not absorption by the surface of cells was also confirmed by a confocal microscope.

Real-time PCR. We used siRNA without $\mathrm{Cy} 3$ for relative molecular experiments. To establish the hVEGF-siRNA silencing efficiency at the mRNA level, a real-time PCR analysis of PC-3 cells was carried out. Total RNA was extracted from the different groups at 2 time-points (after 24 and $48 \mathrm{~h}$ of transfection). Subsequently, reverse transcription to synthesize the cDNA was carried out using the First-Strand cDNA Synthesis kit (Takara, Tokyo, Japan). Real-time PCR was then performed with cDNA using the SYBR ${ }^{\circledR}$ Premix Ex Taq ${ }^{\mathrm{TM}}$ kit (Takara). The final results were evaluated by the $2^{-\Delta \Delta \mathrm{CT}}$ analytical method.

Programmed cell death 5 (PDCD5) as the sensitive index of apoptosis was dynamicly monitored with real-time PCR at 6 time-points (after 2, 6, 12, 24, 48 and $72 \mathrm{~h}$ of transfection). The expression level of PDCD5 was significantly higher during apoptosis than in the normal cells. Therefore, it can be used to further investigate the apoptosis-promoting effects of the VEGF-siRNA interruption in PC-3 cells. PCR primers were designed and producted by the Invitrogen Co. The PCR primer sequences were as follows: VEGF forward, 5'-AAGATCCGC AGACGTGTAAATGTT-3' and reverse, 5'-CGGCTTGTC ACATGCAAGTA-3'; PDCD5 forward, 5'-CTGAGGAGA CAGAGGCTGGC-3' and reverse, 5'-TTTCTGCTTCCCT GTGCTTTG-3'; and the internal standard, GAPDH forward, 5'-CTTAGCACCCCTGGCCAAG-3' and reverse, 5'-GATGTT CTGGAGAGCCCCG-3'.

Detection of apoptosis by flow cytometry. Phosphatidylserine (PS) externalization is one of the main events occurring during the early stages of apoptosis. To detect PS externalization, the transfected cells were harvested by trypsinization and washed twice with PBS. The washed cells were resuspended in $200 \mu \mathrm{l}$ binding buffer (PBS containing $1 \mathrm{mM}$ calcium chloride). FITC-conjugated Annexin V and propidium iodide were added according to the manufacturer's instructions (Biosea Biotechnology Co., Ltd., Beijing, China). After incubation for $20 \mathrm{~min}$ at room temperature, $400 \mu \mathrm{l}$ binding buffer was added, and samples were immediately analyzed on a FACSCalibur flow cytometer (Becton-Dickinson, Franklin Lakes, NJ, USA) 


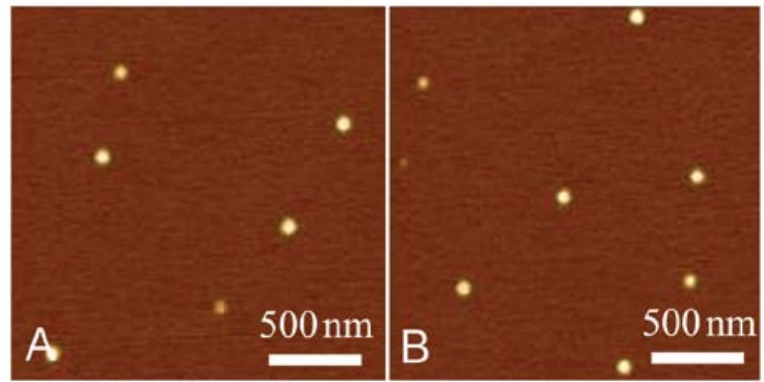

Figure 1. The mPEG-PLGA-PLL siRNA-loaded NPs had a spherical structure under an atomic force microscope. (A) NNPs loaded with siRNA; (B) TNPs loaded with siRNA. Scale bars represent $500 \mathrm{~nm}$.

with excitation using a $488 \mathrm{~nm}$ argon ion laser. The samples were stained with propidium iodide (PI) to distinguish necrotic and late apoptotic events from early apoptotic events. The experiment was also monitored at 6 time-points by analyzing PDCD5 expression (after 2, 6, 12, 24, 48 and $72 \mathrm{~h}$ of transfection). Similar to real-time PCR, flow cytometry is still able to cover the wide dynamic range required for quantification.

VEGF protein assay with ELISA. The detection of VEGF protein expression following transfection was carried out by ELISA quantitative assay. Cells were plated on a 12-well plate at a density of $1.5 \times 10^{5}$ cells/well. After $48 \mathrm{~h}$ of incubation, the medium was replaced by fresh medium without $10 \%$ FBS and the desired siRNA formulations were added to the cells. PC-3 cell culture supernatant was collected after 12, 24 and $48 \mathrm{~h}$ of transfection. The human-VEGF-ELISA kit (4iBIO, Beijing, China) was used to determine VEGF protein expression according to the manufacturer's instructions.

Cell viability assay. We performed trypan blue assay immediately after the cells were treated to measure the transient cytotoxicity of UTMD and NPs. The cells were then analyzed under a microscope to determine the proportion of positive blue-stained cells.

Clonogenic assay. To investigate the effect of the siRNA interruption on the proliferative ability of cells, and to evaluate the side-effects induced by UTMD or NPs, clonogenic cell survival assay was carried out. Cell viability depends not only on the intact cell membrane but also on many other factors. PI commonly used in sonoporation studies or drug toxicity, may not be a reliable measure of cell long-term viability.

After incubation for $48 \mathrm{~h}$ at $37^{\circ} \mathrm{C}$, the 12 groups of cells were trypsinized and seeded into 12 -well plates (100 cells/well). Ordinary culture medium was added. Two weeks later, colonies were fixed and stained with Giemsa, and clones containing $>10$ cells were counted. Each group was assayed in triplicate wells.

Statistical analysis. Data are expressed as the means and standard deviation (means \pm SD). An independent samples t-test was used to determine the significance of the difference between 2 groups. The Kruskal-Wallis test was used to examine the significance by multiple comparisons. Differences were considered significant at $\mathrm{P}<0.05$. Statistical analysis was performed with a software package (SPSS, version 13.0; SPSS, Chicago, IL, USA).

\section{Results}

Analysis of transfection efficiency. TNPs loaded with siRNA delivered by UTMD were observed in the perinuclear cytoplasmic region by a confocal microscope (Fig. 2), which was the first step towards successful gene transfection. Fig. 3A shows the fluorescence images of the cellular uptake of siRNA in the different groups. Examination of the cultured PC-3 cells with a flow cytometer showed that the T3 group (TNPs + UTMD) had a maximal fluorescence intensity index (27.18 \pm 0.91$)$ among all the groups, slightly higher than the N3 group (NNPs + UTMD) $(18.39 \pm 0.90)(\mathrm{P}<0.05)$, while the T3 group demonstrated a significant difference compared to the other control groups $(\mathrm{P}<0.001)$ (Fig. 3B).

Real-time PCR. To establish the inhibitory effect of hVEGFsiRNA at the mRNA level, relative VEGF mRNA expression levels was evaluated after 24 and $48 \mathrm{~h}$ of transfection. The results showed that the T3 group ranked last at $24 \mathrm{~h}(71 \%)$ (Fig. 4A)and $48 \mathrm{~h}$ (53\%) (Fig. 4B), while the N3 group showed similar results to the T3 group at $24 \mathrm{~h}(70 \%)$ and $48 \mathrm{~h}(70 \%)$. The 2 groups showed inhibitory effects as compared to the other samples $(\mathrm{P}<0.05)$. No difference between these groups
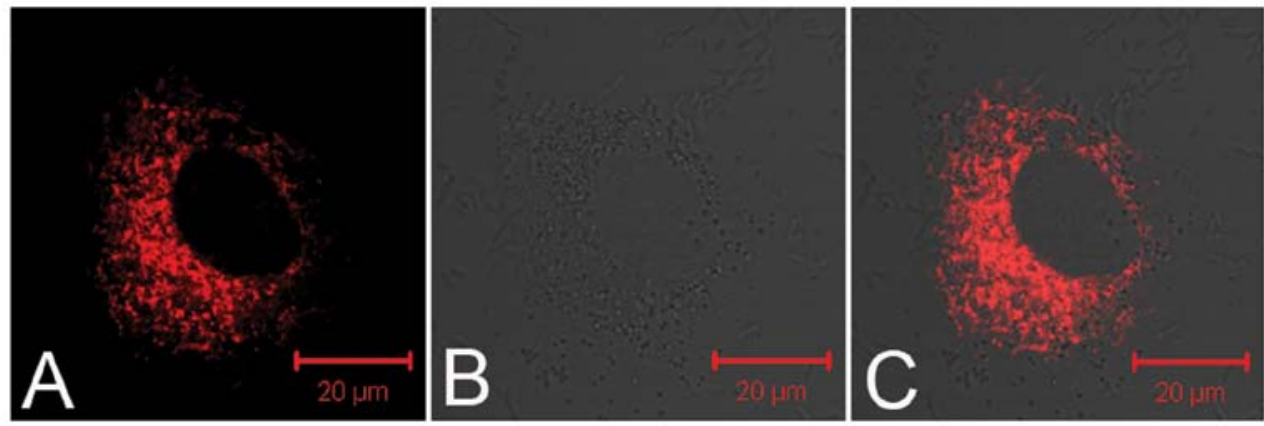

Figure 2. Localization of intracellular TNPs loaded with Cy3-labeled siRNA. PC-3 cells were treated with TNPs loaded with Cy3-labeled siRNA and observed at x1,000 magnification under a confocal microscope. (A) Cy3 red fluorescence in PC-3 cells; (B) white light image of PC-3 cells; (C) a merged image of (A and B). Scale bars represent $20 \mu \mathrm{m}$. 

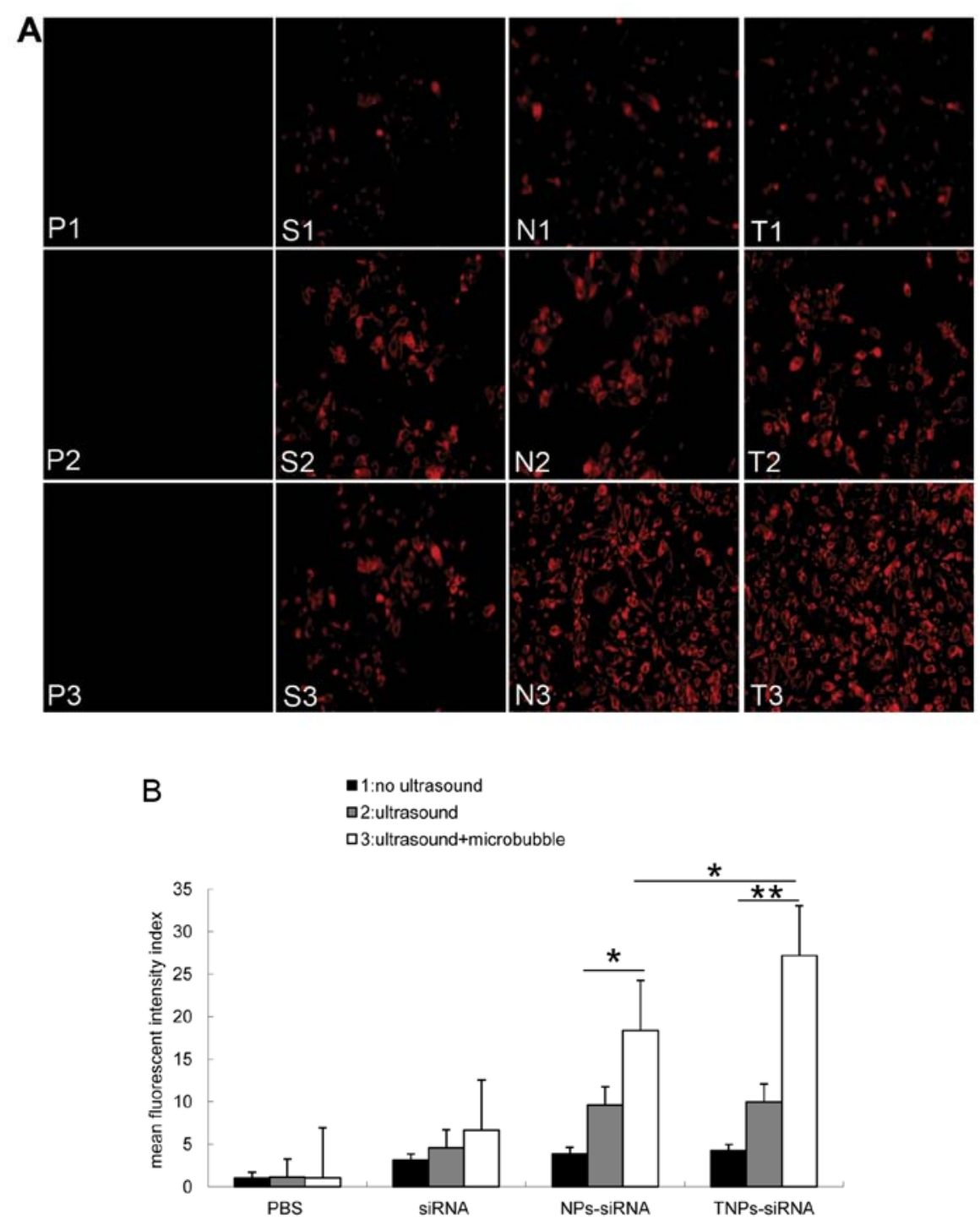

Figure 3. Intracellular uptake of different Cy3-labeled siRNA formulations after $48 \mathrm{~h}$ of transfection. (A) Fluorescence images of the 12 groups under a fluorescent microscope; (B) comparison of mean fluorescence intensity of the 12 groups using flow cytometry. The quantity of fluorescence in the T3 group was slightly higher than that of the $\mathrm{N} 3$ group $\left({ }^{*} \mathrm{P}<0.05\right)$, significantly higher than the other groups $\left({ }^{* *} \mathrm{P}<0.001\right)$.
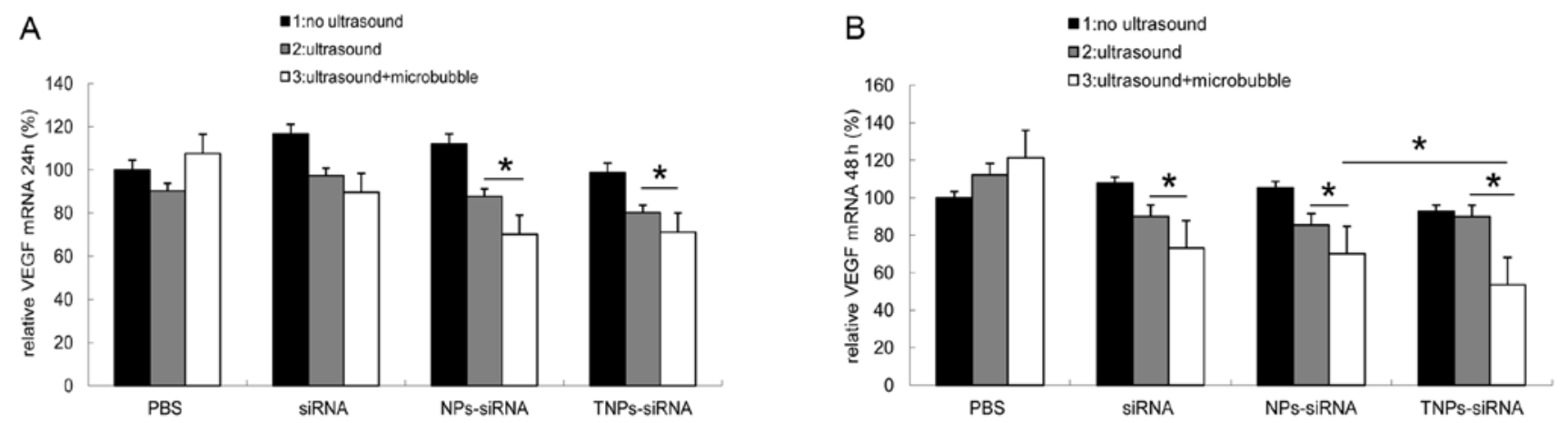

Figure 4. Real-time PCR analysis for relative VEGF mRNA expression in the different groups. (A) Comparison of relative VEGF mRNA expression after $24 \mathrm{~h}$ of transfection. The VEGF mRNA level of N3 and T3 groups ranked last ( $(\mathrm{P}<0.05)$; there was no difference between the 2 groups. (B) Comparison of relative VEGF mRNA expression after $48 \mathrm{~h}$ of transfection. The VEGF mRNA level of the T3 group was significantly lower than the other groups, including the N3 group $($ P $<<0.05)$.

was observed at $24 \mathrm{~h}$, but a significant difference was observed between these groups at $48 \mathrm{~h}(\mathrm{P}<0.05)$.
Given that cell apoptosis can be induced by hVEGF-siRNA, as a sensitive index of cell apoptosis, PDCD5 mRNA expres- 

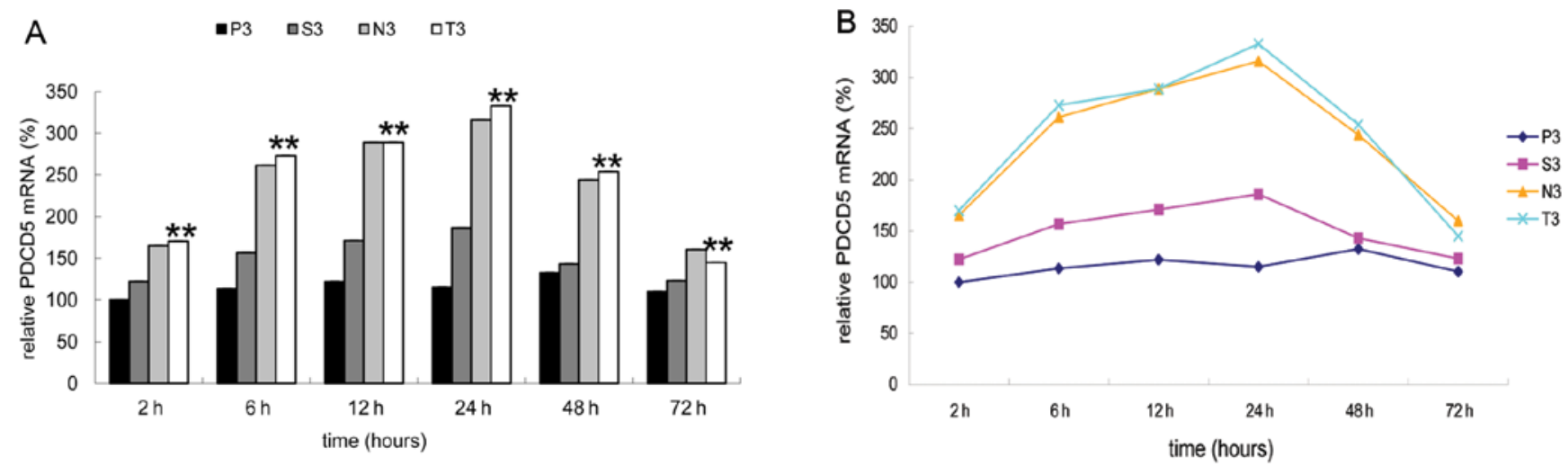

Figure 5. PDCD5 mRNA level in the 4 groups treated by UTMD was evaluated using real-time PCR after 2, 6, 12, 24, 48 and $72 \mathrm{~h}$ of transfection. (A) The mRNA levels in the N3 and T3 groups were significantly higher than the P3 and S3 groups at different time-points ( $\left.{ }^{* *} \mathrm{P}<0.001\right)$, while no difference was observed between 2 groups. (B) PDCD5 mRNA expression increased from 2 to $24 \mathrm{~h}$ and decreased from 48 to $72 \mathrm{~h}$.
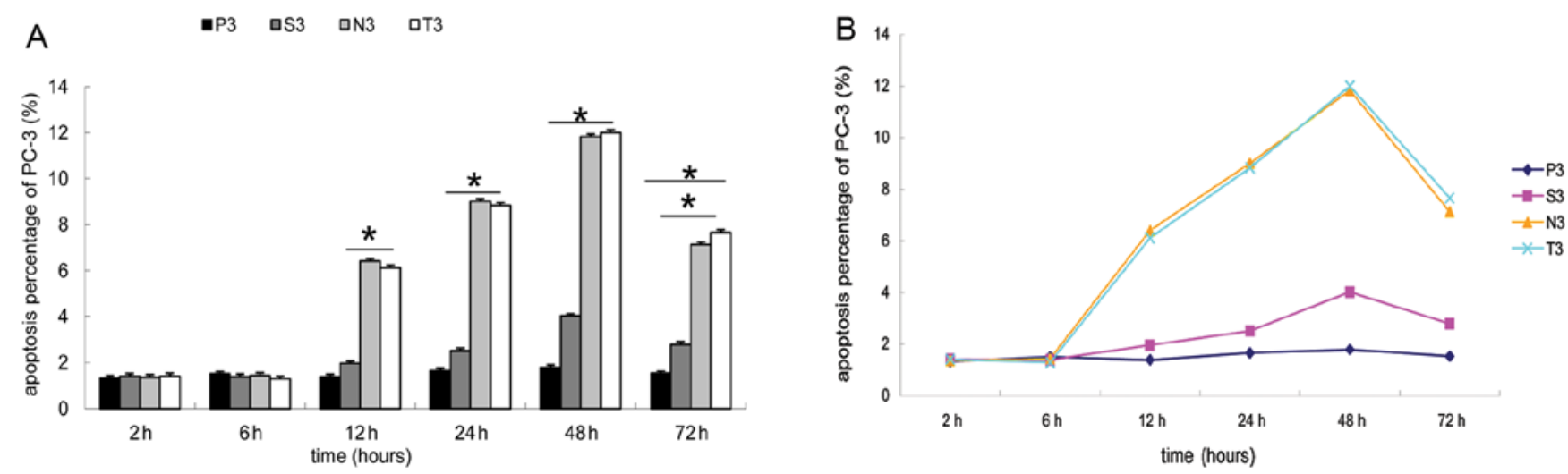

Figure 6. Apoptosis analysis of the 12 groups by flow cytometry after 2, 6, 12, 24, 48 and $72 \mathrm{~h}$ of transfection. (A) Apoptosis in the N3 and T3 groups was significantly higher than the $\mathrm{P} 3$ and $\mathrm{S} 3$ groups after $12 \mathrm{~h}$ of transfection ("P<0.05), while no differernce was observed between N3 and T3 groups. (B) The apoptotic percentage increased after $12 \mathrm{~h}$ of transfection, reached the peak at $48 \mathrm{~h}$ and then decreased gradually.

sion can reflect the gene silencing effect of siRNA indirectly and was therefore examined by real-time PCR analysis. Cell apoptosis is a complex process involving many stages; therefore, we selected 6 time-points to depict the expression trend. The results of real-time PCR analysis demonstrated that all the control groups without microbubbles added and the $\mathrm{P} 3$ group had very similar performance characteristics. No difference was observed in PDCD5 mRNA expression beween these groups at different time-points (data not shown). However, there was no significant difference between the N3 and T3 groups $(\mathrm{P}<0.20)$, showing that the targeted group failed to exceed the non-targeted group concerning inhibitory effects, while differences were noted when compared to the $\mathrm{S} 3$ and $\mathrm{P} 3$ groups, $(\mathrm{P}<0.001)$ (Fig. 5A). Fig. 5B shows that PDCD5 mRNA levels in the N3 and T3 groups remarkably increased with time after $2 \mathrm{~h}$ of transfection, and reached the peak (3-fold the expression of P3) at $24 \mathrm{~h}$, then decreased significantly, while the S3 group (naked siRNA-transfected cells) displayed a weak increase at all time-points.

Detection of apoptosis by flow cytometry. Similar to the results of PDCD5 analysis, the 8 groups without microbubbles showed similar results to the $\mathrm{P} 3$ group, while no difference was observed between the $\mathrm{N} 3$ and $\mathrm{T} 3$ group $(\mathrm{P}<0.15)$ (Fig. 6A).
The difference was that the cell apoptotic percentage in the $\mathrm{N} 3$ and T3 groups notably increased after $12 \mathrm{~h}$ of transfection $(\mathrm{P}<0.05)$, and reached the peak (6.7-fold the percentage of $\mathrm{P} 3)$ at $48 \mathrm{~h}$, then decreased slightly (Fig. 6B). This shows that PS externalization began later than PDCD5 mRNA alteration during early apoptosis.

ELISA. In order to maximally reduce protein secretion induced by the number of cells, the 12-24 $\mathrm{h}$ growth rate (GR) and $24-48 \mathrm{~h}$ GR were compared among the groups. The T3 group showed the lowest protein GR (20\% at both time-points), while the N3 group had the lowest GR (31 and 33\%) (Fig. 7). Compared with the other control groups, the protein expression of the T3 group was significantly suppressed, demonstraring a statistical significance compared with the $\mathrm{N} 3$ group $(\mathrm{P}<0.05)$. In this experiment, the $\mathrm{S} 3, \mathrm{~N} 3$ and $\mathrm{T} 3$ groups showed a significant decline in GR $(\mathrm{P}<0.05)$, indicating that the UTMD method can be used for efficient gene delivery. The GR was determined using the following equation: GR $=$ [protein quatity of $24 \mathrm{~h}$ $(48 \mathrm{~h})$ - protein quatity of $12 \mathrm{~h}(24 \mathrm{~h}) /$ protein quatity of $12 \mathrm{~h}$ (24 h)] x100\%.

Cell viability assay. Under optimized conditions, no significant difference in cell viability was observed between the groups 


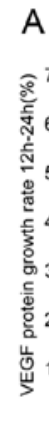

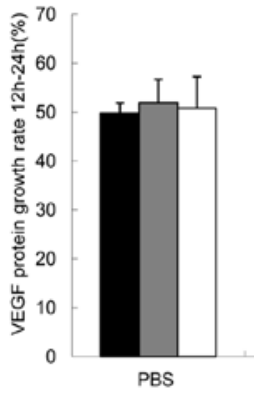

-1:no ultrasound

a2.ultrasound

口3:ultrasound+microbubble

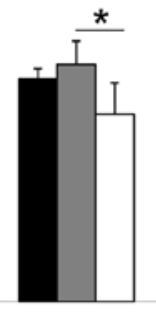

SiRNA
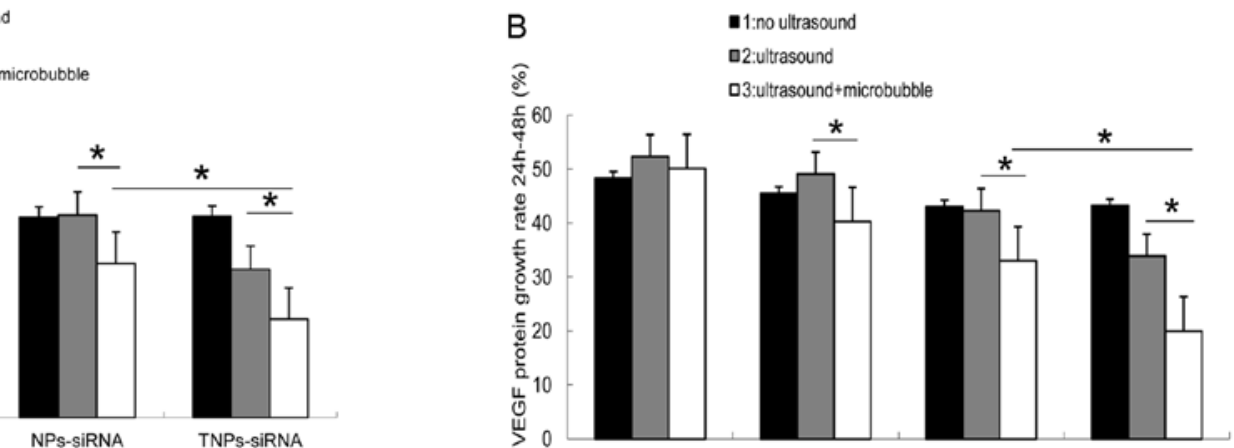

Figure 7. ELISA analysis for relative VEGF protein level in the 12 groups. (A) Comparison of VEGF protein growth rate (GR) from 12 to 24 h. The GR in the $\mathrm{T} 3$ group was significantly lower than the other groups, including the N3 group ( $\mathrm{P}<0.05)$. (B) Comparison of VEGF protein GR from 24 to 48 h. The GR in the T3 group was significantly lower than the other groups, including the $\mathrm{N} 3$ group $\left({ }^{*} \mathrm{P}<0.05\right)$.

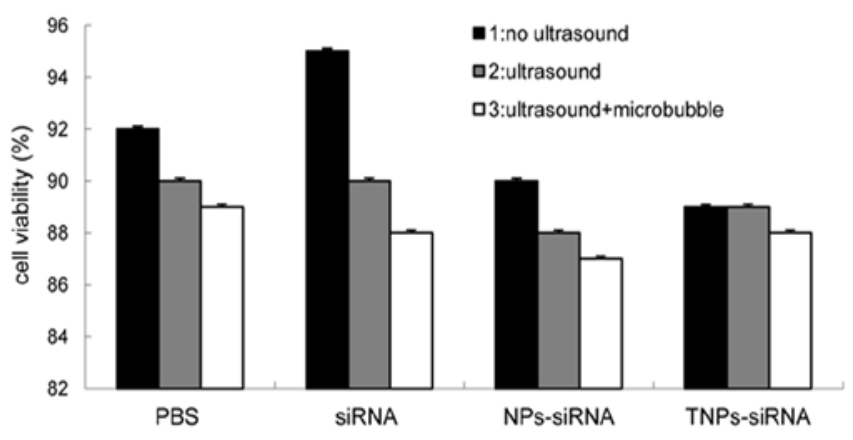

Figure 8. Transient cell viability assay was carried out using trypan blue staining immediately after the cells were treated. The 12 groups showed no significant difference between each other.

$(\mathrm{P}<0.5)$ (Fig. 8). The results demonstrated that cell membrane integrity remained intact during the different treatments and was not be affected by UTMD and NPs. Although UTMD is thought to assist the delivery of molecules into a cell by transiently increasing the membrane permeability, cell membrane integrity would be restored in a short while.

Clonogenic assay. The cell colonies formed by the 12 groups are shown in Fig. 9A. There was no significant difference between these groups (P1, P2, P3, S1, N1 and T1) (Fig. 9B), which demonstrated that UTMD technology and NPs loaded with siRNA had no potential to inhibit cells to proliferate. The number of cell colonies formed by the $\mathrm{S} 2, \mathrm{~N} 2$ and $\mathrm{T} 2$ groups was less than the groups mentioned above; however, there was no statistical significance. The N3 and T3 groups formed the least number of cell colonies, significantly less than the other groups $(\mathrm{P}<0.05)$, which demonstrates that the proliferative ability of the cells had been badly impaired by hVEGF-siRNA delivered with NPs combined with UTMD. There was no difference observed between these 2 groups $(\mathrm{P}<0.1)$ and the $\mathrm{S} 3$ group ranked in the middle position.

\section{Discussion}

Prostate cancer is one of the most common types of cancer and the main leading cause of cancer-related mortality in males. Most late stage prostate cancer patients may become non-responsive to hormone therapy, resulting in deterioration and even death. To date, no single or combination therapy has shown efficacy in inhibiting tumor progression. Genetic therapies represent promising approaches for the treatment of this neoplastic disease. Hormone refractory PC-3 prostate cancer cellss and siRNA targeting the hVEGF gene were selected in our study. It is known that the instability and poor cellular uptake of siRNA has limited its usefulness. To minimize the loss of siRNA and increase cellular uptake efficiencies, hVEGF-siRNA were encapsulated in biodegradable NPs and were delivered into the cell plasma by sonoporation induced by UTMD, which was expected to achieve the downregulation of VEGF gene expression, and to inhibit tumor cell proliferation and induce tumor cell apoptosis.

In our previous study, we successfully constructed NPs made of mPEG-PLGA-PLL triblock copolymers (8). As a nonviral siRNA delivery vector, its stability and biocompatibility, lower cytotoxicity and higher gene transfection efficiency was verified. On the basis of these studies, cRGD ligands were conjugated to the surface of mPEG-PLGA-PLL triblock copolymers to recognize the target site, integrin $\alpha v \beta 3$, highly expressed in PC-3 cells. cRGD is a commonly-used ligand in many targeting studies for specific recognition $(17,18)$. Targeted NPs loaded with siRNA combined with UTMD techonology were used to further improve the gene delivery efficiencies.

We used siRNA labeled with $\mathrm{Cy} 3$ for morphological experiments. After the intracellular localization of TNPs was confirmed, the fluorescence intensity of the T3 group was the highest among the 12 groups, which indicated that much more TNPs were aggregated and adhered on the surface of PC-3 cells with the help of the targeting ligand, cRGD.

SiRNA without Cy3 was used for relative molecular experiments. Real-time PCR (for the mRNA level) and ELISA (for the protein level) were carried out to identify the direct inhibitory effect of hVEGF-siRNA. The results showed that VEGF expression decreased significantly at both levels. ELISA demonstrated that the VEGF protein GR of the T3 group was $<40 \%$ of the P3 group, while less than $68 \%$ of the N3 group at the 2 time-points. These may be the most significant results in this study, showind that cRGD had a targeting effect similar to that shown in previous studies $(19,20)$. The S3, N3 and T3 groups showed a significant decline in GR comared with the other groups $(\mathrm{P}<0.05)$, demonstrating that UTMD as driving force was an effective method to facilitate gene delivery. 

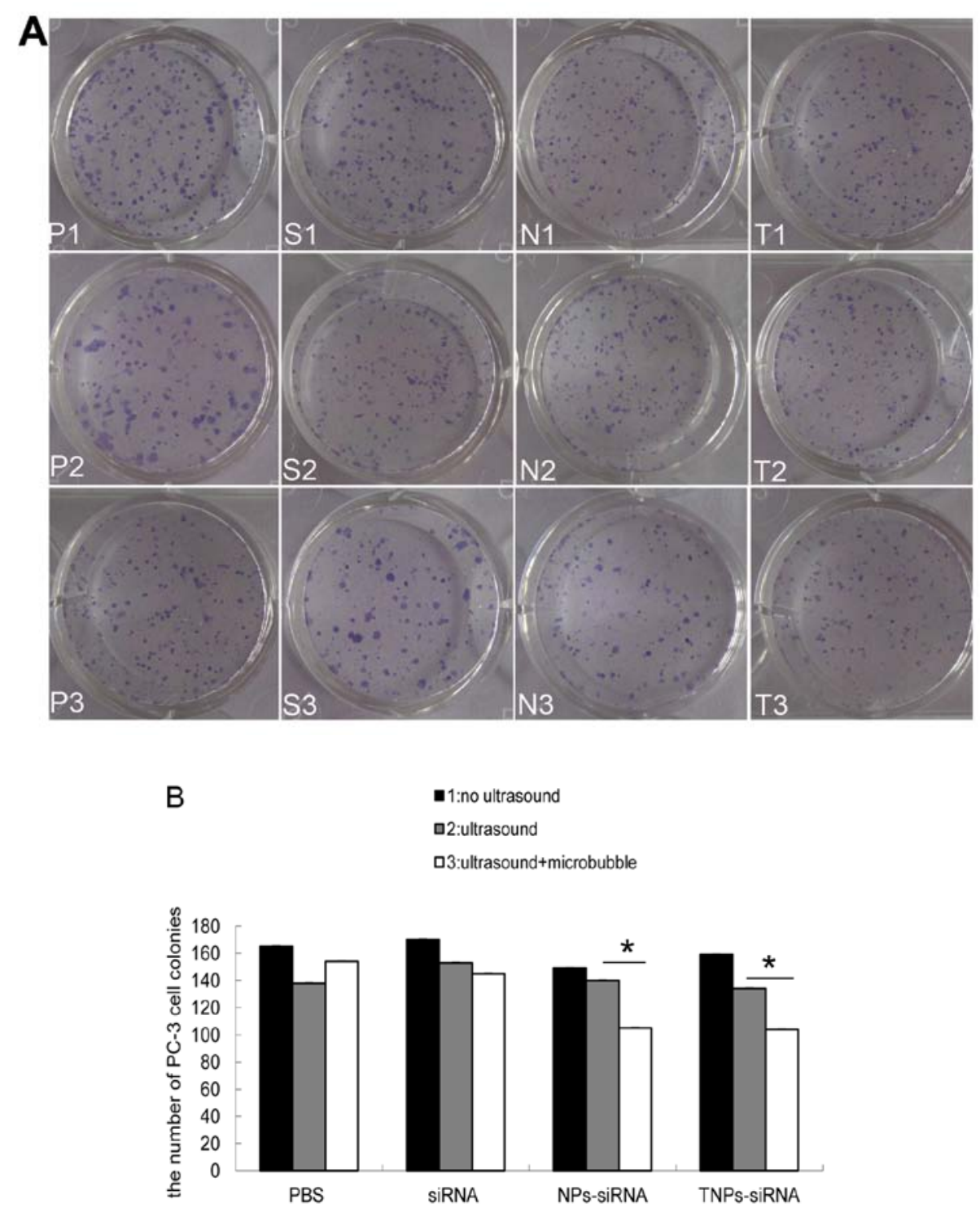

Figure 9. Long-term cell viability was analyzed by a cell colony experiment after $48 \mathrm{~h}$ of transfection. (A) Cell colonies formed by PC-3 cells with different treatments. (B) Comparison of the number of cell colonies formed by PC-3 cells with different treatments. The number of colonies formed in the N3 and T3 groups was significantly lower than the other groups $\left({ }^{*} \mathrm{P}<0.05\right)$, while there was no difference between the 2 groups $(\mathrm{N} 3$ and $\mathrm{T} 3)$.

To examine the induction of apoptosis by the siRNAmediated inhibition of VEGF expression in PC-3 cells $(21,22)$, the detection of apoptosis by flow cytometry and real-time PCR was carried out after $2 \mathrm{~h}$ of transfection. A biochemical hallmark of apoptotic cell death is the translocation of PS from the cytoplasmic surface of the cell membrane to the external cell surface (23). The levels of PS in apoptotic cells is easily determined by flow cytometry using fluorescence-labelled Annexin V, which specifically binds PS. The overexpression of PDCD5 precedes the chromosome DNA fragmentation and PS externalization during early apoptosis. PDCD5 mRNA and protein levels are upregulated in response to various apoptotic stimuli (24-26). Therefore, PDCD5 mRNA levels were aslo determined by real-time PCR in our study. As the other 8 groups showed a similar trend with the $\mathrm{P} 3$ group, the 4 groups (P3, S3, N3 and T3) which demonstrated significant differences are described in this study. The results of flow cytometry demonstrated that apopotosis of PC-3 cells occurred after $6 \mathrm{~h}$ of transfection and reached the peak at $48 \mathrm{~h}$, while the results of PDCD5 analysis showed that apopotosis began after $2 \mathrm{~h}$ of transfection and reached the peak at $24 \mathrm{~h}$. PDCD5 has been consistently regarded as a more sensitive index during early apoptosis as it has been reported that the upregulation of PDCD5 mRNA precedes PS externalization during early apoptosis (27). This was also determined in our study. Certain studies have shown that PDCD5 is possibly involved in the 2 cell death programs, apoptosis and paraptosis, and that it may be one of the key molecules connecting these 2 processes $(28,29)$. However, the targeting effect of the cRGD ligands was similar to that of the than non-targeted NPs in the 2 experiments. Combined with the VEGF expression results presented above, although we obtained some results with statistical significance, from the perspective of absolute value, the results were limited. The reasons why the gene silencing effect of the TNP-siRNA complexes failed to dramatically exceed that of the NNP-siRNA may be as follows: although the physicochemical characterization of the NNPs loaded with siRNA was introduced in our previous study, whether the combination 
of cRGD has an impact on the inherent nature of NPs should be verified; therefore, further experiments for constructing TNPs of perfect quality are warranted. siRNA which were not connected to a self-replication vector lacked biological amplification effects; experimental conditions should be further optimized; and a number of tumor cell lines should be selected, taking into account the differences between cell lines.

Trypan blue assay showed that UTMD methods and different NPs had no significant effect on transient cell viability. MPEG-PLGA-PLL NPs turned out to be stable, biodegradable and biocompatible, without hampering the metabolic activity of the cells as revealed by the results of our previous study (8). A number of studies have indicated the side-effects of inertial cavitation induced by UTMD, such as cell apoptosis and cell lysis $(30,31)$, capillary rupture (32), hemolysis (33), etc. In our study, UTMD did not induce transient cell viability decrease under optimized conditions. Adverse effects were directly related to microbubble nature and ultrasound exposure conditions. The side-effects should be reduced to a minimum by optimization.

We selected clonogenic cell survival assay to further investigate the long-term effect of siRNA and the cytoxity of UTMD and NPs. The N3 and T3 groups formed the least number of cell colonies, demonstrating the long-term effect of NPs loaded with siRNA, which should be mainly attributed to the longer-lasting siRNA release from the NPs $(34,35)$. Apart from the S3 group, the number of colonies of the other 9 groups remained similar. The UTMD and NPs failed to damage the ability of the PC-3 cells to form colonies and proliferate. The study by Karshafian et al demonstrated that approximately half of the cells undergoing reversible permeabilization retained their long-term viability (36). Perhaps the utilization of NPs facilitates the delivery of siRNA; therefore, side-effects were significantly reduced with lower ultrasound exposure parameters and less quatities of reagents, as shown in our study.

Novel biodegradable targeted NPs combined with UTMD were expected to significantly facilitate gene transfection. However, not all experimental results in this study indicated that the TNPs had a more powerful inhibitory effect than the NNPs. The results from our study indicate that NPs combined with UTMD can synergistically serve as a non-viral gene delivery system without notable cell toxicity. Although some positive results were obtained, the small number of samples and the fact that the experiments were only repeated a few times may be the first limitation of the present study. Secondly, it was impossible to avoid the disturbance of certain personal factors, instrument errors and environmental alterations. Thirdly, this study was limited to in vitro study. In conclusion, repeated experiments are necessary to verify the feasibility of this novel gene delivery system and further studies using animal models are required.

\section{Acknowledgements}

This study was supported by grants from the National Natural Science Foundation of China (nos. 81171352/H1805 and 81000617), the National Natural Science Foundation of China (no. 81272568 and 81101738), Biological Pharmaceutical and Agriculture Fields from Science and Technology Commission of Shanghai Municipal (no. 114119a 3300).

\section{References}

1. Namiecińska M, Marciniak K and Nowak JZ: VEGF as an angiogenic, neurotrophic, and neuroprotective factor. Postepy Hig Med Dosw (Online) 59: 573-583, 2005 (In Polish).

2. Anai S, Sakamoto N, Sakai Y, Tanaka M, Porvasnik S, Urbanek C, Cao W, Goodison S and Rosser CJ: Dual targeting of Bcl-2 and VEGF: a potential strategy to improve therapy for prostate cancer. Urol Oncol 29: 421-429, 2011.

3. Tao J, Tu YT, Huang CZ, Feng AP, Wu Q, Lian YJ, Zhang LX, Zhang XP and Shen GX: Inhibiting the growth of malignant melanoma by blocking the expression of vascular endothelial growth factor using an RNA interference approach. Br J Dermatol 153: 715-724, 2005.

4. Rhee J and Hoff PM: Angiogenesis inhibitors in the treatment of cancer. Expert Opin Pharmacother 6: 1701-1711, 2005.

5. Sitohy B, Nagy JA and Dvorak HF: Anti-VEGF/VEGFR therapy for cancer: reassessing the target. Cancer Res 72: 1909-1914, 2012.

6. Chakraborty C: Potentiality of small interfering RNAs (siRNA) as recent therapeutic targets for gene-silencing. Curr Drug Targets 8: 469-482, 2007.

7. McNamara JO II, Andrechek ER, Wang Y, Viles KD, Rempel RE, Gilboa E, Sullenger BA and Giangrande PH: Cell type-specific delivery of siRNAs with aptamer-siRNA chimeras. Nat Biotechnol 24: 1005-1015, 2006.

8. Du J, Sun Y, Shi QS, Liu PF, Zhu MJ, Wang CH, Du LF and Duan YR: Biodegradable nanoparticles of mPEG-PLGA-PLL triblock copolymers as novel non-viral vectors for improving siRNA delivery and gene silencing. Int J Mol Sci 13: 516-533, 2012.

9. Vamer JA and Cheresh DA: Tumor angiogenesis and the role of vascular cell integrin alphavbeta3. Important Adv Oncol 1: 69-87, 1996.

10. Eliceiri BP and Cheresh DA: The role of alphav integrins during angiogenesis: insights into potential mechanisms of action and clinical development. J Clin Invest 103: 1227-1230, 1999.

11. Zheng DQ, Woodard AS, Fornaro M, Tallini G and Languino LR: Prostatic carcinoma cell migration via alpha(v)beta3 integrin is modulated by a focal adhesion kinase pathway. Cancer Res 59: 1655-1664, 1999

12. Li HL, Zheng XZ, Wang HP, Li F, Wu Y and Du LF: Ultrasoundtargeted microbubble destruction enhances AAV-mediated gene transfection in human RPE cells in vitro and rat retina in vivo. Gene Ther 16: 1146-1153, 2009.

13. Carson AR, McTiernan CF, Lavery L, Hodnick A, Grata M, Leng X, Wang J, Chen X, Modzelewski RA and Villanueva FS: Gene therapy of carcinoma using ultrasound-targeted microbubble destruction. Ultrasound Med Biol 37: 393-402, 2011.

14. Shohet RV and Grayburn PA: Potential bioeffects of ultrasonic destruction of microbubble contrast agents. J Am Coll Cardiol 47: 1469-1470, 2006.

15. Lai CY, Wu CH, Chen CC and Li PC: Quantitative relations of acoustic inertial cavitation with sonoporation and cell viability. Ultrasound Med Biol 32: 1931-1941, 2006.

16. Ay T, Havaux X, Van Camp G, Campanelli B, Gisellu G, Pasque A, Denef JF, Melin JA and Vanoverschelde JL: Destruction of contrast microbubbles by ultrasound: effects on myocardial function, coronary perfusion pressure and microvascular integrity. Circulation 104: 461-466, 2001.

17. Xie J, Shen Z, Li KC and Danthi N: Tumor angiogenic endothelial cell targeting by a novel integrin-targeted nanoparticle. Int $\mathrm{J}$ Nanomedicine 2: 479-485, 2007.

18. Lin RY, Dayananda K, Chen TJ, Chen CY, Liu GC, Lin KL and Wang YM: Targeted RGD nanoparticles for highly sensitive in vivo integrin receptor imaging. Contrast Media Mol Imaging 7: 7-18, 2012.

19. Mu Y, Li L and Ayoufu G: Experimental study of the preparation of targeted microbubble contrast agents carrying urokinase and RGDS. Ultrasonics 49: 676-681, 2009.

20. Dayton PA, Pearson D, Clark J, Simon S, Schumann PA, Zutshi R, Matsunaga TO and Ferrara KW: Ultrasonic analysis of peptide- and antibody-targeted microbubble contrast agents for molecular imaging of alphavbeta3-expressing cells. Mol Imaging 3: 125-134, 2004.

21. Rong W, Wang J, Liu X, Jiang L, Wei F, Hu X, Han X and Liu Z: Naringin treatment improves functional recovery by increasing BDNF and VEGF expression, inhibiting neuronal apoptosis after spinal cord injury. Neurochem Res 37: 1615-1623, 2012. 
22. Ferrari G, Pintucci G, Seghezzi G, Hyman K, Galloway AC and Mignatti P: VEGF, a prosurvival factor, acts in concert with TGF-betal to induce endothelial cell apoptosis. Proc Natl Acad Sci USA 103: 17260-17265, 2006.

23. Fadok VA, Bratton DL, Frasch SC, Warner ML and Henson PM: The role of phosphatidylserine in recognition of apoptotic cells by phagocytes. Cell Death Differ 5: 551-562, 1998.

24. Liu H, Wang Y, Zhang Y, Song Q, Di C, Chen G, Tang J and Ma D: TFAR19, a novel apoptosis-related gene,cloned from human leukemia cell line TF-1, could enhance apoptosis of some tumor cells induced by growth factor withdrawal. Biochem Biophys Res Commun 254: 203-210, 1999.

25. Xu L, Chen Y, Song Q, Xu D, Wang Y and Ma D: PDCD5 interacts with Tip60 and functions as a cooperator in acetyltransferase activity and DNA damage-induced apoptosis. Neoplasia 11: 345-354, 2009.

26. Zhuge C, Chang Y, Li Y, Chen Y and Lei J: PDCD5-regulated cell fate decision after ultraviolet-irradiation-induced DNA damage. Biophys J 101: 2582-2591, 2011.

27. Chen Y, Sun R, Han W, Zhang Y, Song Q, Di C and Ma D: Nuclear translocation of PDCD5 (TFAR19): an early signal for apoptosis? FEBS Lett 509: 191-196, 2001.

28. Jiang J, Wang N, Guan Z and Houshan LV: Programmed cell death 5 factor enhances triptolide-induced fibroblast-like synoviocyte apoptosis of rheumatoid arthritis. Artif Cells Blood Substit Immobil Biotechnol 38: 38-42, 2010.

29. Wang Y, Li X, Wang L, Ding P, Zhang Y, Han W and Ma D: An alternative form of paraptosis-like cell death, triggered by TAJ/ TROY and enhanced by PDCD5 overexpression. J Cell Sci 117: 1525-1532, 2004.
30. Feril LB Jr, Kondo T, Zhao QL, Ogawa R, Tachibana K, Kudo N, Fujimoto $S$ and Nakamura S: Enhancement of ultrasound-induced apoptosis and cell lysis by echo-contrast agents. Ultrasound Med Biol 29: 331-337, 2003.

31. Honda H, Zhao QL and Kondo T: Effects of dissolved gases and an echo contrast agent on apoptosis induced by ultrasound and its mechanism via the mitochondria-caspase pathway. Ultrasound Med Biol 28: 673-682, 2002.

32. Skyba DM, Price RJ, Linka AZ, Skalak TC and Kaul S: Direct in vivo visualization of intravascular destruction of microbubbles by ultrasound and its local effects on tissue. Circulation 98 : 290-293, 1998.

33. Miller MW, Everbach EC, Cox C, Knapp RR, Brayman AA and Sherman TA: A comparison of hemolytic potential of Optison and Albunex in whole human blood in vitro: acoustic pressure, ultrasound frequency, donor and passive cavitation detection considerations. Ultrasound Med Biol 27: 709-721, 2001.

34. Danhier F, Pourcelle V, Marchand-Brynaert J, Jérôme C, Feron O and Préat V: Targeting of tumor endothelium by RGD-grafted PLGA-nanoparticles. Methods Enzymol 508: 157-175, 2012.

35. Liu P, Qi X, Sun Y, Wang H, Li Y and Duan Y: RGD-conjugated PLA-PLL nanoparticles targeting to Bacp-37 breast cancer xenografts in vivo. J Nanosci Nanotechnol 11: 10760-10764, 2011.

36. Karshafian R, Samac S, Bevan PD and Burns PN: Microbubble mediated sonoporation of cells in suspension: clonogenic viability and influence of molecular size on uptake. Ultrasonics 50: 691-697, 2010. 